\title{
Induction process of trainees in pathology residency
}

This article was published in the following Dove Press journal:

Advances in Medical Education and Practice

27 May 2016

Number of times this article has been viewed

\author{
Imran Siddiqui' \\ Natasha $\mathrm{Ali}^{1,2}$ \\ 'Department of Pathology and \\ Laboratory Medicine, ${ }^{2}$ Department of \\ Oncology, The Aga Khan University, \\ Karachi, Pakistan
}

\begin{abstract}
This article describes the evolution of the induction process of pathology residency at The Aga Khan University hospital. The Department of Postgraduate Medical Education was established in 1985. The induction process is an exhaustive exercise that includes an admission test held simultaneously in Karachi, Hyderabad, Lahore, and Rawalpindi, followed by an interview of the shortlisted candidates. The pathology residency program was started 25 years ago and since then the induction process has undergone major changes with the course of time. Keywords: pathology residency, induction process, residency program
\end{abstract}

\section{Discussion}

A topic most frequently debated among clinical laboratory scientists is the impact of health care on clinical laboratories. Scott and Sacks ${ }^{1}$ in 1995 predicted a shortage of community pathologists, academic pathologists, clinical chemists, and medical technologists. Because of this, many training programs saw a rapid expansion of induction processes. In contrast, Wennberg et $\mathrm{al}^{2}$ suggested that the current number of pathologists during this period far exceeded the need in a managed care environment and that in the next 6-7 years of the training program, no pathologists will be required until we eliminate the excess.

The Aga Khan University, Karachi, is a private research university founded in 1983. The hospital was established in 1985 and has been recently reaccredited by the Joint Commission International. The Postgraduate Medical Education (PGME) program at the Aga Khan University provides excellence and innovation in specialized postgraduate education to promote evidence-based health care and research, abiding by the principles of ethics and professionalism. Currently, there are 33 residency programs across the board and residencies in subspecialties of pathology are catered to by the Department of Pathology and Laboratory Medicine. The trainings cater to four different residency programs. The disciplines include chemical pathology, hematology, histopathology, and microbiology. The program was established in 1988 . We have previously published how the residency program has evolved in the last 25 years. ${ }^{3}$ The induction process of the program has also undergone major changes during this time. This article outlines the current process of induction of trainees in the residency program of pathology.

During the foundation years, an interview was conducted by senior faculty members who assessed the candidates. The prerequisite was work experience of 6 months
Correspondence: Natasha Ali

Department of Pathology and Laboratory Medicine, The Aga Khan University, PO Box 3500, Stadium Road, Karachi 74800, Pakistan

Tel +922134861306

Fax +92 21 4934294

Email natasha.ali@aku.edu 
in pathology after MBBS. In 1985, when the Department of PGME was established, the induction process was formalized with perpetual improvements.

Currently, the process starts with the announcement of the new induction cycle, advertised mid-year through the PGME office in all leading newspapers of Pakistan. It is also advertised on the University's website, which contains basic information of the program and eligibility criteria. After the introduction of residency in pathology at the College of Physicians and Surgeons, Pakistan, the mandatory requirement now is passing Fellow of College of Physicians and Surgeons, Pakistan, part I exam in Pathology based on the guidelines of College of Physicians and Surgeons, Pakistan. As a rule, only online applications are accepted and candidates can apply in one program only at a given time. There are two application deadlines to accommodate the varied graduation dates of different medical colleges across the country.

Following the application, candidates take an admission test in their respective fields. The test also has an English language component that helps in identifying candidates who require English language coaching classes if he/she is selected; these classes are provided by the University and funded by the respective departments. The scientific component of the test is based on the curriculum of MBBS and 1 year of internship experience. The exam is held simultaneously in Karachi, Hyderabad, Lahore, and Rawalpindi. Centers outside Karachi are supervised by a team of faculty with a PGME administrative representative. Candidates who have successfully completed a year of internship from The Aga Khan University and graduated are exempted from the written test. The results of the written exam are forwarded to the residency director and departmental residency committee. After the results are compiled, candidates for pathology residency are divided into four sections of clinical chemistry, hematology, histopathology, and microbiology. The results are individually reviewed and candidates with the highest marks are shortlisted for the interview. The interview call is sent to candidates with a ratio of $1: 3$ or $1: 4$ that is, for every vacant seat, there will be three or four top ranking candidates shortlisted for the interview. The final list for the four disciplines is sent to the human resources department, which issues interview letters for the shortlisted candidates and regret letters to the rest.

Every candidate is interviewed by two panels to reduce bias. The panels include members from all four disciplines of pathology and the chief resident faculties with nonrelated specialties comprising of a general panel. The faculty in this panel is not related to the subspecialty that the candidate has applied for. Here, the dialogue with the candidate consists of obtaining general information: reasons for interest in the particular field they have opted for, their likes and dislikes, hobbies, and so on. The second panel is of the respective four sections and consists of members from the same subspecialty. This interview is focused and assesses professional approach, commitment, dedication, knowledge, and communication skills. The candidates also share their thoughts on the working hours and expectations. They are also encouraged to informally meet the senior residents in the department to have a feel of the working environment.

The interview is an exhaustive exercise and at the end individual marks given by each faculty on a standardized form are cumulated. These scores are aggregated by the departmental residency committee and the highest achievers are shortlisted for the final selection. At the end of this exercise, all decisions are made and submitted to the residency director and simultaneously forwarded to the human resources department to issue final selection letters, which are dispatched over a span of 2 weeks. Prior to starting their training, a 3-day orientation program is organized by the PGME. Important aspects of this orientation include welcome address by the Dean Medical College, Associate Dean PGME, followed by lectures from departmental representatives of information technology, security, medical and bioethics, pharmacy, human resources, blood bank and, above all, PGME. This orientation program is attended by all program directors, coordinators, and chief residents who share their personal experience of training and work life. Amid these lectures, the inductees are involved in the making of identification badges and other important paperwork. In pathology, a day is selected during the orientation period in which the chief resident provides a general overview of the program. It primarily focuses upon meeting the faculty and staff, tours of their respective sections, and timetables.

Although most hospitals run an induction program, there is variety in the content and style. Trainees have a diverse range of experience, giving rise to different needs and expectations which may or may not be fulfilled by an induction program. ${ }^{4}$ Service to patients does not stop during the changeover periods. High-quality patient care is provided at all times. An effective departmental induction program rapidly integrates trainees into their posts and reduces trainees' anxieties. A lot of effort is required to design and deliver such a program. Our program is based on the two-staged approach proposed by Ward and Stanley ${ }^{5}$ in 1999, which integrates hospital induction with departmental induction. The induction process has 
come a long way from its initial days when candidates were assessed on an interview with a prerequisite of 6 months training in pathology. Introduction of an entrance exam at multiple centers with separate components followed by an interview has streamlined the process further. Suffice is it to say that we have been able to make a difference in reducing trainees' initial anxieties, enabling them to move comfortably into making an effective contribution to service and profiting from the training provided.

\section{Author contributions}

Both authors contributed toward data analysis, drafting and revising the paper and agree to be accountable for all aspects of the work.

\section{Disclosure}

The authors report no conflicts of interest in this work.

\section{References}

1. Scott MG, Sacks DB. Current status of US programs for training clinical laboratory scientists and anticipated impact of healthcare reform. Clin Chem. 1995;41(6 Pt 1):934-941.

2. Wennberg JE, Goodman DC, Nease RF, Keller RB. Finding equilibrium in U.S. physician supply. Health Aff (Millwood). 1993;12(2): 89-103.

3. Siddiqui I, Ali N, Kayani N. Pathology residency programme of a developing country - Landscape of last 25 years. J Educ Train Stud. 2016;4(3):20-27.

4. Williams JG, Cheung WY. Induction training, career counselling, and performance review: views of junior medical staff. Postgrad Med J. 1998;74(873):411-415.

5. Ward SJ, Stanley P. Induction for senior house officers. Part I: The hospital programme. Postgrad Med J. 1999;75(884):346-350.
Advances in Medical Education and Practice

\section{Publish your work in this journal}

Advances in Medical Education and Practice is an international, peerreviewed, open access journal that aims to present and publish research on Medical Education covering medical, dental, nursing and allied health care professional education. The journal covers undergraduate education, postgraduate training and continuing medical education

\section{Dovepress}

including emerging trends and innovative models linking education, research, and health care services. The manuscript management system is completely online and includes a very quick and fair peer-review system. Visit http://www.dovepress.com/testimonials.php to read real quotes from published authors.

Submit your manuscript here: http://www.dovepress.com/advances-in-medical-education-and-practice-journal 